\title{
Potential Suitable Areas of Giant Ground Sloths Dropped Before its Extinction in South America: the Evidences from Bioclimatic Envelope Modeling
}

\author{
Matheus Souza Lima-Ribeiro ${ }^{1,2 *}$, Sara Varela ${ }^{3}$, \\ David Nogués-Bravo ${ }^{4} \&$ José Alexandre Felizola Diniz-Filho ${ }^{5}$
}

\author{
${ }^{1}$ Departamento de Ciências Biológicas, Universidade Federal de Goiás - UFG, Jataí, GO, Brazil \\ ${ }^{2}$ Programa de Pós-graduação em Ecologia e Evolução, Universidade Federal de Goiás - UFG, Goiânia, GO, Brazil \\ ${ }^{3}$ Department of Ecology, Faculty of Science, Charles University, Czech Republic \\ ${ }^{4}$ Center for Macroecology, Evolution and Climate, University of Copenhagen, Copenhagen Ø, Denmark \\ ${ }^{5}$ Departamento de Ecologia, Instituto de Ciências Biológicas, Universidade Federal de Goiás - UFG, Goiânia, GO, Brazil
}

\begin{abstract}
Here we analyze the effects that climatic changes through last ice age had on the potential distributions and extinction risk dynamics of two extinct species of South American giant ground sloths, Eremotherium laurillardi and Megatherium americanum. We tested the assumption of stability of the climate preferences through time for the two species and modeled their potential distributions at last glacial maximum (LGM, 21 ky BP) and mid-Holocene (6 ky BP) using Bioclimatic Envelope Modeling (BEM), fossil records and paleoclimatic simulations. The model predictions showed a drastic reduction of the geographical ranges for both species during mid-Holocene, along with a considerable fragmentation of their core climatic conditions and refugia, although it did not fully disappear at this time. Thus, our findings point out that the extinction risk of both species greatly increased as a consequence of the climate change, although do not support it as the unique stressor.
\end{abstract}

Key words: Climate Changes, Last Ice Age, Late Quaternary Extinctions, Megafaunal Extinctions, Pleistocene.

\section{Introduction}

We are currently facing a global biodiversity crisis in which species losses reach an unprecedented high rate across past centuries and millennia. Some authors even state that a "sixth mass extinction" is now occurring driven by global warming and human impacts, but it could be avoided if we do success to understand how species and ecosystems react to these stressors (Barnosky et al. 2011). Both extinct and extant Pleistocene species bore global and cyclic climatic changes (Pleistocene glacial-interglacial cycles) and experienced the dispersal of modern humans across all continents as well. Thus, analyses of Pleistocene mammal extinction can provide key elements, together with modern data, to a deeper understand why some species disappear, whereas others survive under human and climate impacts. Such analyses from Pleistocene fossil record would help us responding how these stressors affect species distribution and their extinction risk, giving us significant insights to

*Send correspondence to: Matheus Souza Lima-Ribeiro Departamento de Ciências Biológicas,

Universidade Federal de Goiás - UFG, CP 03,

CEP 75804-020, Jataí, GO, Brazil

E-mail: paleo_ribeiro@yahoo.com.br tentatively reverse the current trends of global biodiversity loss (Jablonski 2004; Hadly \& Barnosky 2009).

Under this context, we analyze here the geographical range dynamics of two Pleistocene extinct species, Eremotherium laurillardi and Megatherium americanum (hereafter Eremotherium and Megatherium, respectively) as response to climate changes through the last glacial cycle. These giant ground sloths (Megatheriids) lived in South America during the Pleistocene and disappeared in the early Holocene (Cartelle \& De Iuliis 2006; Politis \& Messineo 2008). Eremotherium lived in tropical and subtropical forests, whereas Megatherium inhabited temperate arid to semiarid environments (Bargo et al. 2006; Nascimento 2008).

We use Bioclimatic Envelope Modeling (BEM) in a paleobiogeographical context to analyze the effects of climate changes through last ice age on potential distributions and extinction risk dynamics of these two species. We test the assumption of stability of the climate preferences through time for the two species and model their potential distributions at the LGM and mid-Holocene. The models showed a drastic reduction of the geographical ranges of 
both species from LGM to mid-Holocene, along with a fragmentation of their core climatic conditions and refugia. However, climatically suitable conditions for those species did not fully disappear during the mid-Holocene. Thus, our results point out that the extinction risk of both species greatly increased as a consequence of the climate change, although do not support it as the unique stressor.

\section{Material and Methods}

\section{Climate predictors and occurrence record sampling}

Past climatic conditions were compiled for both LGM (21 ky BP) and mid-Holocene (6 ky BP) from six coupled Atmosphere-Ocean General Circulation Models (AOGCMs; see details in in the Additional Supporting Information, Table S1, available at www.abeco.org.br), and downscaled to a grid with $0.5^{\circ}$ resolution covering the entire Neotropics. We downloaded four climate variables from AOGCMs outputs (monthly simulation for precipitation, and mean, maximum and minimum temperature) and computed five bioclimatic variables (annual mean temperature, temperature annual range, precipitation of wettest and driest month, and precipitation of warmest quarter) as predictors to build the BEMs. LGM and mid-Holocene represent, respectively, the coldest and warmest phases through the last glacial cycle. Thus, these are two "key" periods for modeling the past distributions of South American giant ground sloths to evaluate how climate change affected their extinction risks.

The occurrence records for the two species of extinct South American giant ground sloths were obtained from the dated fossil remains available in the literature (see Tables S2-S3). The fossil records dated at glacial times (60 for Eremotherium and 34 for Megatherium - 60-E/34-M) were used as 'training' data to calibrate the BEMs, whereas those dated around Pleistocene-Holocene boundary ( 11 ky BP; 14/9) were used as 'independent test' data to validate the BEM's projections at the interglacial period. Detailed description about the climate layers and fossil record is available in Supporting Information.

\section{Quality of fossil record and their implications to the models}

The majority of the fossil record $(\sim 80 \%)$ was dated from indirect associations (i.e., relating remains into a same dated layer; 14-E/5-M) or by relative ones (i.e., assigning a relatively wide interval to that fossil occurrence, like late Pleistocene or Lujanian ages; 44-E/26-M), and some records ( 20\%) were directly dated based on animal remains (e.g., bone - 5-E/7-M; Table S1). Because the small amount of fossil remains for both Eremotherium and Megatherium in South America, we use all information available about their fossil occurrences for mapping their past distributions from BEMs. Further, we used also conservative criteria to link the fossil occurrences to the paleoclimatic simulations. For each species, all directly- and indirectly-dated fossil evidences at glacial times ( $45 \mathrm{ky}$ BP to $15 \mathrm{ky} \mathrm{BP}$ ), as well as relatively-dated remains (i.e., Lujanian or Pleistocene ages), were linked to the LGM (21 ky BP) paleoclimate and used to calibrate the models. Hence our working assumption was that the individual fossil dated as a late Pleistocene or Lujanian age might have survived at LGM.

We emphasize that the fossil records available for South American giant ground sloths and used here to calibrate the BEMs might yield over- or under-estimate of their past distributions. However, we did not aim at fully describe the real locations where each species existed through the last glacial cycle (i.e., realized distribution; for this we would necessity of a much better stratigraphic and taphonomic control for the fossil record), but rather to analyze how the potential geographical range size of these species shifted (expansion/contraction) through this period and if climate changes may had drove them to extinction. Although the initial conditions might influence the models over- or under-estimating the predicted potential geographical ranges (Elith \& Leathwick 2009; Franklin 2009), we provided robust evaluation to the model predictions. We evaluated the predictive performance using independent test data (independent validation), tested the assumption of stability of the climatic conditions occupied by species through time and finally used the multi-temporal calibration approach to build the BEMs (see text below).

For instance, the independent validation indicated that the climatic preferences of both species remained constant through last glacial cycle. Using then the fossil occurrences from glacial periods to calibrate the BEMs (the multitemporal calibration approach) ensures that the same modeling bias (if some) will occur in all time periods (the potential distribution will be over- or under-estimated in all periods). So, the dynamic of predicted potential distribution through time (i.e., increase/decrease of climatically suitable areas available to the species survival from one time period to another) would not be due to initial conditions related to fossil record quality, but to effects of climate changes through those time periods. To deal analytically with this issue we performed a hierarchical ANOVA to partition the uncertainties from components (methods, AOGCMs, species and time) used to build the BEMs. Methods and AOGCMs were crossed in a two-way factorial design and nested in species, which in turn were nested in time (see details in Terribile et al. 2012). This approach reveals that variance around the model predictions through time is higher than methodological uncertainties (methods and AOGCMs), suggesting then that effects of climate change through time on the potential distributions of both species are more expressive than that from relatively low quality of fossil records. We believe therefore our models are reliable to assess the effects of climate changes on geographical range dynamic of both Megatheriidae in South America. 


\section{Mapping past distributions and their uncertainties}

The geographical ranges were first modeled for LGM and then projected onto mid-Holocene scenario to obtain the species distribution at both glacial and interglacial periods, respectively. We used the BioEnsembles platform (see DinizFilho et al. 2009) to implement five presence-only algorithms (Bioclim, ENFA, Euclidean distance, Gower distance, and Mahalanobis distance; see Supporting Information for more details about BioEnsembles platform, algorithms selection, and model building). Next, the suitability values were classified in quartiles for mapping regions with different climatic suitability (suitability decreases from first - Q1 - to fourth quartile - Q4). We tested the stability of climatic conditions occupied by species through last glacial cycle, which is an important assumption when the geographical range is projected on different climatic scenarios through time (Nogués-Bravo 2009). We used the CCM1 AOGCM to predict the potential distribution at $11 \mathrm{ky} \mathrm{BP}$ (see Supporting Information), and computed how many records at that time were predicted as species' presence. Moreover, this test for stability of climate conditions occupied by giant ground sloths through time may well be considered also as an adequate validation approach from independent test data (Nogués-Bravo 2009). Regardless, we assessed the predictive performance using true skill statistics (TSS) based on cross-validation approach (75\% training, 25\% test).

Also, we used a two-way Analysis of Variance (ANOVA) without replication (Zar 1999) to partition the sources of uncertainties affecting the ensemble solution. We used the standardized suitability values as dependent variable and methods and AOGCMs as factors (see Diniz-Filho et al. 2009). The proportion of sum of squares explained by each source of uncertainty was then obtained for each grid cell and mapped, allowing evaluating where each effect is more important in explaining past distributions.

\section{Assessing the range shift and extinction risk}

We computed the range size at LGM and mid-Holocene and the "range shift" (difference between range sizes through time). We also assessed the sources of uncertainty related to range shifts through last glacial cycle performing again a two-way ANOVA without replication (Zar 1999) using methods and AOGCMs as factors (see Diniz-Filho et al. 2009).

Finally, we mapped the climatically stable areas through time (i.e. refugia) for both species and evaluated their extinction risk at the end of the Pleistocene using the classification schemes from IUCN red list criteria (see http://www.iucnredlist.org/). IUCN criteria for threat classification rely on many aspects such as population dynamic and size, extent of occurrence and/or area of occupancy, and quantitative analyses (population viability). Our evaluation for extinction risk of Megatheriids from
IUCN red list criteria might thus be biased since we use only estimates of geographical range size through time (which may indicate population size, sense IUCN, assuming a given fixed density - IUCN criteria A e B; but see discussion below). However, it certainly indicates as much the climate changes throughout last glacial cycle affected both species in South American at the end of the Pleistocene by constrain and fragment their geographical ranges, so raising their extinction risk.

\section{Results}

The consensus maps showed a drastic reduction in potential distributions for both species from LGM to mid-Holocene (Figures 1, 2). For Eremotherium, around $80 \%$ of most climatically suitable conditions (Q1/Q2) were lost in this period. The largest range shift of both species occurred just in northern South America, although the lesser suitable conditions (Q4) have considerably increased in this region towards the mid-Holocene. Besides narrow, a fragmented distribution of the most climatically suitable conditions is also observed in mid-Holocene for both species (Figure 1). Moreover, the climatically stable areas since LGM (i.e. refugia) were also scarce and disjoint for both species.

The models describing the past distributions of South American Megatheriids showed relatively good fits for both species and all AOGCMs, with TSS values usually higher than 0.2. Moreover, the interglacial projections from all presence-only algorithms predicted at least one half of the independent test data (dated fossil record around $11 \mathrm{ky} \mathrm{BP}$ ) and were then used in the ensemble solution.

Furthermore, the potential distribution at LGM from consensus maps (Figure 1) matches the individual fossil record locations during late Pleistocene in South America (see Nascimento 2008). The consensus maps show a northward and southward distribution for Eremotherium and Megatherium, as expected by their preferences for tropical and temperate climates, respectively (see Bargo et al. 2006; Nascimento 2008 and references therein). These climatic preferences are also shown for mid-Holocene (Figure 1) and from refugium areas for both species.

Although the consensus maps have adequately described the main climatic preferences for both South American giant ground sloths, the models from each BEM and AOGCMs showed considerable variation. In all cases, the main source of uncertainty comes from BEMs, followed by interaction between BEMs and AOGCMs (Table 1). Further, spatial patterns of the predictive uncertainty largely vary among algorithms, AOGCMs and their interaction. The uncertainties for species' range shift, however, came from a different source. For Eremotherium, the main variation comes from BEMs, whereas for Megatherium it comes from AOGCMs (Table 1). More details are provided in Supporting Information, Figures S1-S6 and Tables S1-S5. 


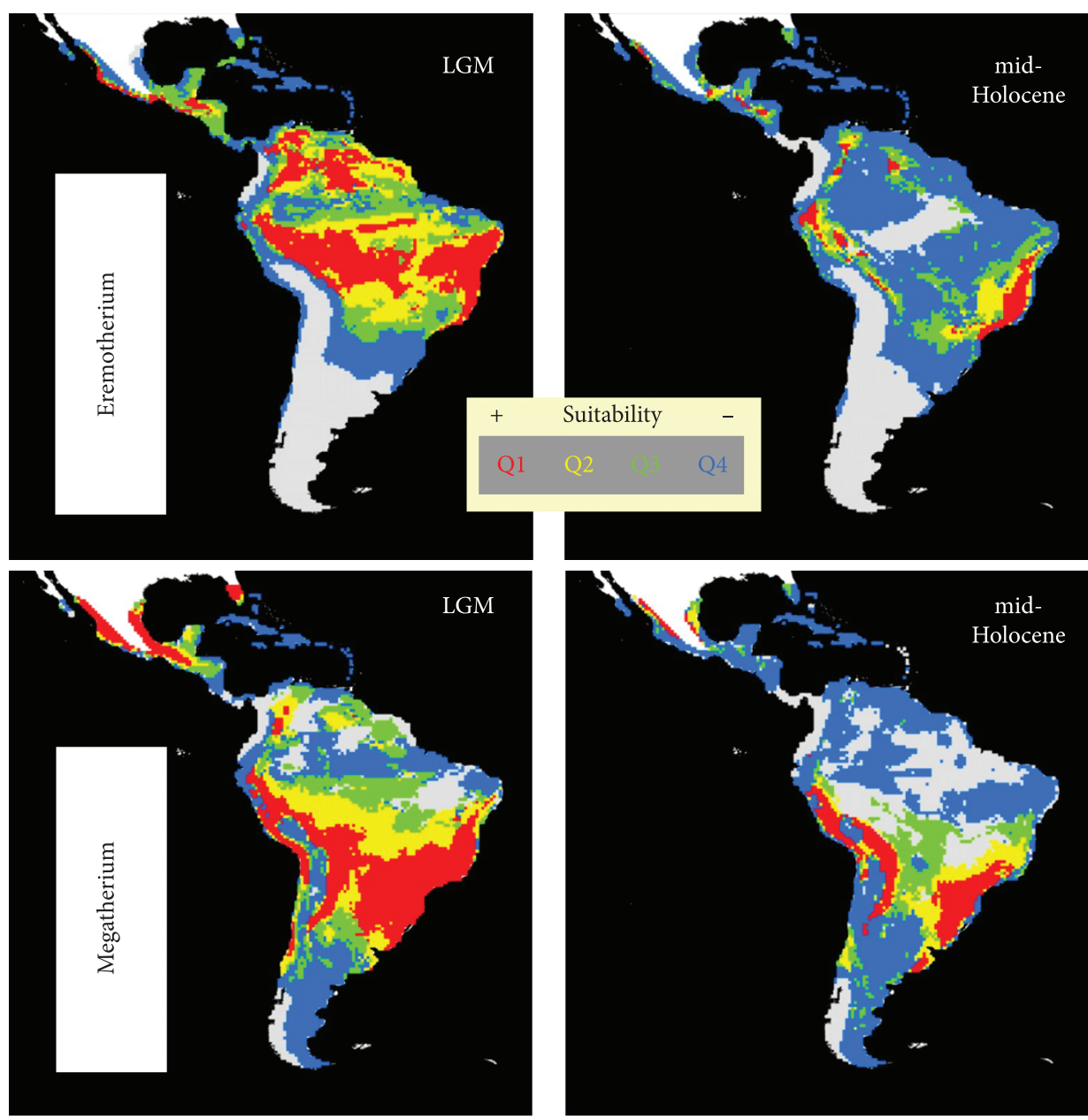

Figure 1. Ensemble of predictive maps showing the potential distribution of Eremotherium (upper) and Megatherium (bottom) at LGM and mid-Holocene. The colors indicate the quartiles of climatically suitable conditions (suitability decreases from Q1, in red, to Q4, in blue). Note the scattered distribution of the most suitable conditions (Q1 and Q2) of both giant ground sloths at mid-Holocene.

Table 1. Relative contribution of each modeling component (method and AOGCM) to the variability in model predictions for both giant ground sloths. The values for LGM and mid-Holocene refer to the median proportions of total sum of squares from two-way ANOVA performed for each grid cell covering the Neotropics (see also Figures S5-S6). The third column of each species (RANGE SHIFT) shows the relative contribution of the modeling components to the variability in geographical range shift (difference of range sizes between LGM and mid-Holocene). ${ }^{*}$ The residuals are just the interaction between the factors ( method $^{\star} \mathrm{AOGCM}$ ).

\begin{tabular}{lcccccccc}
\hline \multirow{2}{*}{ Factor } & \multicolumn{3}{c}{ Eremotherium } & & \multicolumn{2}{c}{ Megatherium } \\
\cline { 2 - 4 } & LGM & mid-Holocene & RANGE SHIFT & & LGM & mid-Holocene & RANGE SHIFT \\
\hline Method & 79 & 45 & 21.7 & & 48 & 42 & 31.8 \\
AOGCM & 3 & 7 & 66.6 & & 8.8 & 10 & 21.8 \\
Residuals $^{*}$ & 17 & 42 & 11.7 & & 39 & 45 & 46.5 \\
\hline
\end{tabular}

\section{Discussion}

\section{Extinction risk and geographical range dynamics of South American giant ground sloths}

Our findings based on BEMs show clear effects of climate change on potential distributions, range shifts and extinction risk of both Eremotherium and Megatherium. However, the models do not show a full collapse of all climatically suitable conditions in mid-Holocene. For instance, the lesser suitable conditions (Q4) considerably increased towards mid-Holocene (Figure 2), especially in northern South America (Figures S2-S3). Based on the classification established by IUCN, the threat category of both giant ground sloths through last glacial cycle should undoubtedly be set as "threatened", at least in its lowest-risk subcategory called "vulnerable" (i.e., considering an estimated population size 

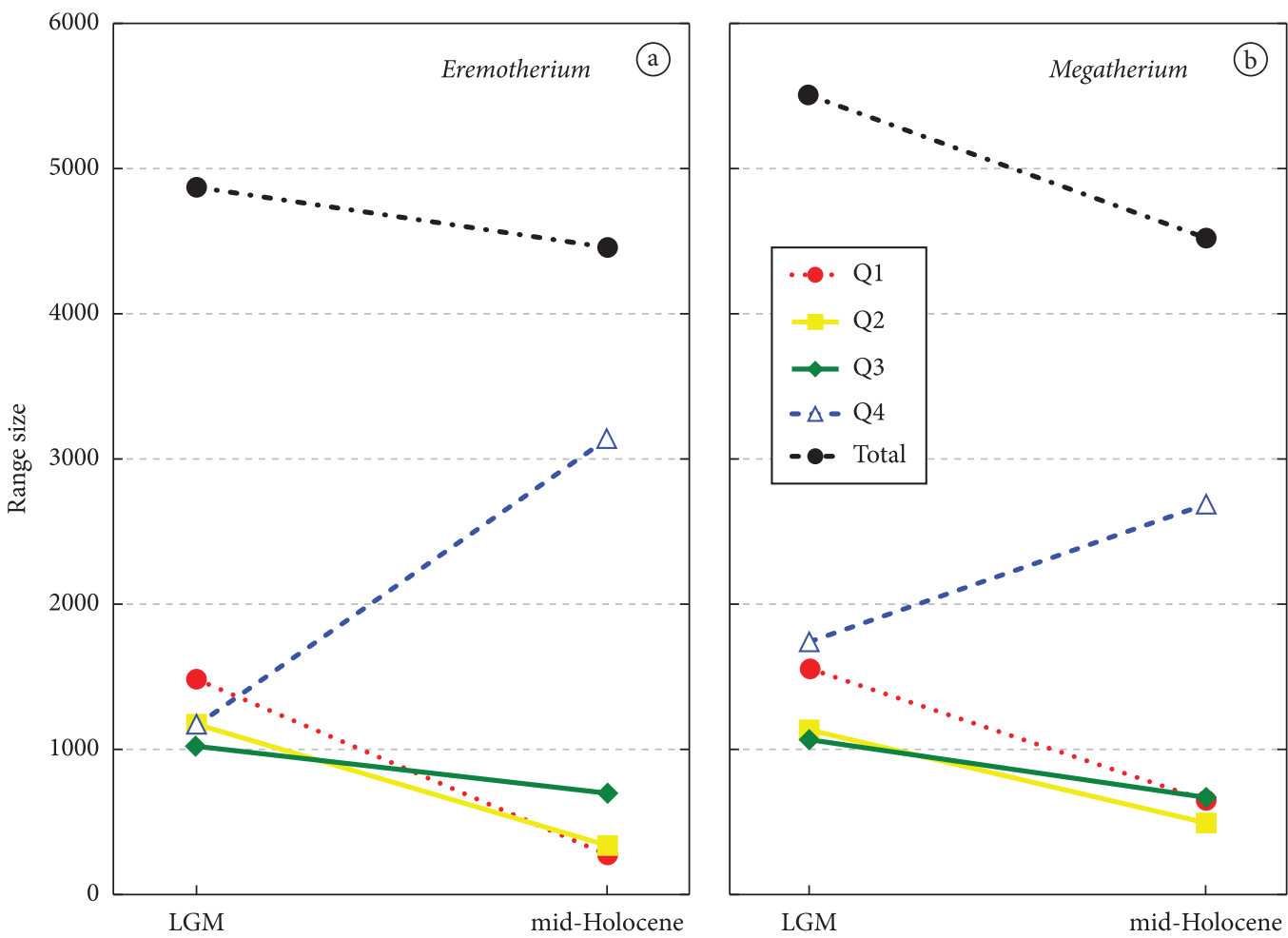

Figure 2. Geographical range size (number of grid cells) of Eremotherium (a) and Megatherium (b) at LGM and mid-Holocene. The color lines indicate the quartiles of climatically suitable conditions, which decrease from Q1, in red, to Q4, in blue. Black line indicates the full range size (sum of all quartiles). Note the large decrease in area of the most suitable conditions for both giant ground sloths.

reduction of $>50 \%$ - A1 -, continuing decline and extreme fluctuation in geographical range, as well as ranges severely fragmented - B1). In this case, the vulnerable subcategory means that both species would be severely threatened at mid-Holocene, but not fully extirpated, by climate change effects alone.

Large-bodied species must occupy wider areas than smallbodied ones to get enough resources to survival (Kelt \& Van Vuren 2001). As consequence, the extinction risk raises when such large-bodied species are constrained to small ranges (Purvis et al. 2000). So, the disappearance and fragmentation of climatically suitable (Figure 1) and stable conditions (Figure S4) towards mid-Holocene may be potentially a key factor increasing the extinction risk of both Megatheriids in South America through the last glacial cycle. Indeed, the extinction risk raises faster when species geographical range decline for a substantial period of time in response to climate changes because the populations might to reach size below of minimum viable size (Foote et al. 2007). Moreover, a large-bodied mammal like giant ground sloths should occur locally at relatively low densities because of their high energetic requirements (equivalence energetic rule, Damuth 1981). A relatively small contraction in their potential geographical range (and realized one) could thus cause a large reduction in their overall population densities. Hence, a simple stochastic event would drive species to extinction, or at least would greatly increase their extinction risk, especially when their small populations were scattered by climate changes. Our analyses clearly show that climate changes must undoubtedly had been an important driver of past distributions and extinction risk of giant ground sloths during late Pleistocene and early Holocene in South America.

Some empirical studies, such as Nogués-Bravo et al. (2008) and Lorenzen et al. (2011), have recently demonstrated that the synergy between both climate and human impacts is the most plausible explanation for the megafaunal extinction at the end of the Pleistocene (see also Koch \& Barnosky 2006; Prescott et al. 2012). Human impacts (direct or indirect) would be larger and more deleterious the smaller the geographical range of megafaunal species was. In our case, humans arriving in South America around 15-13.5 ky BP (Rothhammer \& Dillehay 2009), just at starting of the interglacial period and when both species of giant ground sloths were scattered and narrowly distributed due to climate change, might have impacted the populations of Eremotherium and Megatherium leading them definitively to extinction. Cutting marks and associations with human archaeological tools indicate that humans exploited those species (Politis \& Messineo 2008; Dantas et al. 2012; but see a diferent interpretation in Borrero 2009).

Pleistocene mammal's extinction event in South America was likely the cause of synergetic effects of climate change 
and humans, as it likely was in Europe, North America and Australia (Koch \& Barnosky 2006; Borrero 2009). Climate change caused shifts in species geographical ranges, but most of the times, there was not the ultimate factor of the species extinctions (Martínez-Meyer et al. 2004; Nogués-Bravo et al. 2008; Lorenzen et al. 2011). In the case of South American giant ground sloths, climate change increased species extinction risk by dropping and fragmenting their potential climatically suitable and stable areas. In this scenario, human impacts possibly have played a definitive role, diminishing the chances for the scattered populations to recover from the climatic crisis. Therefore, the extinction of South American giant ground sloths at the end of the Pleistocene may well illustrate that additive effect between multiple stressors is potentially more dangerous to species survival than just one single stressor.

\section{Modeling bioclimatic envelopes and distributions for extinct species}

We illustrate here the potential of integrating BEMS, the fossil record and paleoclimatic simulations to understand past extinctions. Nevertheless, the use of BEM in a paleobiogeographical context requires extra caution comparable to neoecological one because important assumptions are inherently linked to this framework, like stability of ecological niche through time (Nogués-Bravo 2009; Svenning et al. 2011; Varela et al. 2011).

In our case, for instance, the inter-temporal projections showed that climatic conditions occupied by both species did not considerably change across last ice age. Consequently, species' bioclimatic envelopes calibrated in the glacial scenario (LGM) correctly predicted their climatic preferences at interglacial one ( 11 ky BP). Moreover, the correspondence between our model predictions and those described in other studies (see Bargo et al. 2006; Nascimento 2008 and references therein) show that BEMs were able to capture the main climatic preference of both species from their glacial fossil records and increase our reliability about the past distributions presented here. Hence, we consider that the climatic effects on the potential distribution of South American giant ground sloths predicted here are accurate and represent a good approximation to evaluate the dynamic of their potential distributions though last ice age.

\section{Acknowledgements}

We thank Thiago F. Rangel for access to Bioensembles platform used here for BEM analyses. We acknowledge the World Climate Research Programmer's Working Group on Coupled Modeling, which is responsible for CMIP5, and we thank the climate modeling groups (listed in Table S1 of this paper) for producing and making available their model outputs. We thank Prof. Cástor Cartelle and Andrés Rinderknecht for their useful advice. M.S. Lima-Ribeiro thanks FAPEG for graduated fellowship. S. Varela is supported by the project: "Support of establishment, development, and mobility of quality research teams at the Charles University“, registration number CZ.1.07/2.3.00/30.0022, supported by The Education for Competitiveness Operational Programme (ECOP) funded by the ESF and the government budget of the Czech Republic. D.N.B. thanks the Danish National Research Foundation for support to the Center for Macroecology, Evolution and Climate. J.A.F. Diniz-Filho has been continuously supported by productivity grants from $\mathrm{CNPq}$. The figures, when possible, were built thinking in the color-blind peoples; thanks the authors of the color pallet from <http://jfly.iam.u-tokyo.ac.jp/html/color_blind/>.

\section{References}

Bargo M, Iuliis G \& Vizcaíno SF, 2006. Hypsodonty in Pleistocene ground sloths. Acta Palaeontologica Polonica, 51:53-61. http://dx.doi.org/10.4202/app.2009.0116

Barnosky AD et al., 2011. Has the Earth's sixth mass extinction already arrived? Nature, 471:51-57. http://dx.doi.org/10.1038/ nature 09678

Borrero LA, 2009. The elusive evidence: the archeological record of the South American extinct megafauna. In: Haynes G (ed.). American megafaunal extinctions at the end of the Pleistocene. Reno: Springer Science. p. 145-168. http:// dx.doi.org/10.1007/978-1-4020-8793-6_8

Cartelle C \& De Iuliis G, 2006. Eremotherium laurillardi (Lund) (Xenarthra, Megatheriidae), the Panamerican giant ground sloth: taxonomic aspects of the ontogeny of skull and dentition. Journal of Systematic Palaeontology, 4:199-209. http://dx.doi.org/10.1017/S1477201905001781

Damuth J, 1981. Population-density and body size in mammals. Nature, 290:699-700. http://dx.doi.org/10.1038/290699a0

Dantas M, Queiroz A \& Santos F, 2012. An anthropogenic modification in an Eremotherium tooth from northeastern Brazil. Quaternary International, 253:107-109. http://dx.doi. org/10.1016/j.quaint.2011.09.019

Diniz-Filho JAF et al., 2009. Partitioning and mapping uncertainties in ensembles of forecasts of species turnover under climate change. Ecography, 32:897-906. http://dx.doi. org/10.1111/j.1600-0587.2009.06196.x

Elith J \& Leathwick JR, 2009. Species distribution models: ecological explanation and prediction across space and time. Annual Review of Ecology, Evolution, and Systematics, 40:677-697. http://dx.doi.org/10.1146/annurev. ecolsys.110308.120159

Foote $\mathrm{M}$ et al., 2007. Rise and fall of species occupancy in Cenozoic fossil mollusks. Science, 318:1131-1134. http:// dx.doi.org/10.1126/science.1146303

Franklin J, 2009. Mapping species distributions: spatial inference and predictions. Cambridge: Cambridge University Press.

Hadly EA \& Barnosky AD, 2009. Vertebrate fossils and the future of conservation biology. In: Dietl GP \& Flessa KW (eds.). Conservation Paleobiology: using the past to manage for the future. Lubbock: The Paleontological Society. p. 39-59.

Jablonski D, 2004. Extinction: past and present. Nature, 427:589. PMid:14961099. http://dx.doi.org/10.1038/427589a 
Kelt DA \& Van Vuren DH, 2001. The ecology and macroecology of mammalian home range area. The American Naturalist, 157: 637-645. http://dx.doi.org/10.1086/320621

Koch PL \& Barnosky AD, 2006. Late Quaternary extinctions: state of the debate. Annual Review of Ecology, Evolution, and Systematics, 37:215-250. http://dx.doi.org/10.1146/ annurev.ecolsys.34.011802.132415

Lorenzen ED et al., 2011. Species-specific responses of Late Quaternary megafauna to climate and humans. Nature, 479:359-365. http://dx.doi.org/10.1038/nature10574

Martínez-Meyer E, Peterson AT \& Hargrove WW, 2004. Ecological niches as stable distributional constraints on mammal species, with implications for Pleistocene extinctions and climate change projections for biodiversity. Global Ecology and Biogeography, 13:305-314. http://dx.doi. org/10.1111/j.1466-822X.2004.00107.x

Nascimento ER, 2008. Os Xenarthra Pilosa (Megatheriidae), Notoungulata (Toxodontidae) e Proboscidea (Gomphotheriidae) da formação Rio Madeira, Pleistoceno Superior, estado de Rondônia, Brasil. [Tese]. Porto Alegre: Universidade Federal do Rio Grande do Sul.

Nogués-Bravo D, 2009. Predicting the past distribution of species climatic niches. Global Ecology and Biogeography, 18:521-531. http://dx.doi.org/10.1111/j.1466-8238.2009.00476.x

Nogués-Bravo D et al., 2008. Climate change, humans, and the extinction of the woolly mammoth. PLoS Biology, 6:685-692. http://dx.doi.org/10.1371/journal.pbio.0060079

Politis G \& Messineo P, 2008. The Campo Laborde site: New evidence for the Holocene survival of Pleistocene megafauna in the Argentine Pampas. Quaternary International, 191:98114. http://dx.doi.org/10.1016/j.quaint.2007.12.003

Prescott GW et al., 2012. Quantitative global analysis of the role of climate and people in explaining late Quaternary megafaunal extinctions. Proceedings of the Notional Academy of Sciences USA, 109:4527-4531. http://dx.doi.org/10.1073/ pnas.1113875109

Purvis A et al., 2000. Predicting extinction risk in declining species. Proceedings of the Royal Society B, 267:1947-1952. http://dx.doi.org/10.1098/rspb.2000.1234

Rothhammer F \& Dillehay TD, 2009. The Late Pleistocene colonization of South America: an interdisciplinary perspective. Annals of Human Genetics, 73:540-549. http:// dx.doi.org/10.1111/j.1469-1809.2009.00537.x

Svenning J-C et al., 2011. Applications of species distribution modeling to paleobiology. Quaternary Science Reviews, 30:2930-2947. http://dx.doi.org/10.1016/j. quascirev.2011.06.012

Terribile LC et al., 2012. Areas of climate stability in the Brazilian Cerrado: disentangling uncertainties through time. Natureza \& Conservação, 10(2): 152-159. http:// dx.doi.org/10.4322/natcon.2012.025

Varela S, Lobo JM \& Hortal J, 2011. Using species distribution models in paleobiogeography: a matter of data, predictors and concepts. Palaeogeography, Palaeoclimatology, Palaeoecology, 310:451-463. http://dx.doi.org/10.1016/j. palaeo.2011.07.021

Zar JH, 1999. Biostatistical analysis. 4th ed. New Jersey: Prentice Hall.

Received: September 2012

First Decision: October 2012

Accepted: October 2012 